\title{
Los interlocutores y campos figurativos en un poema. El caso de un poema de Vicente Huidobro y otro de Blanca Varela
}

The interlocutors and figurative fields in a poem. The case of a poem by Vicente Huidobro and another by Blanca Varela

\section{Camilo Rubén Fernández-Cozman \\ Universidad de Lima \\ crferna@ulima.edu.pe \\ https://orcid.org/ 0000-0002-7474-8666}

Para referenciar este artículo:

Fernández, C. R. (2021). Los interlocutores y campos figurativos en un poema. El caso de un poema de Vicente Huidobro y otro de Blanca Varela. Revista ConCiencia EPG, 6(1), 76-83.

\section{Resumen}

1 locutor y el alocutario son dos figuras centrales en el texto poético. El artículo analiza el papel del locutor y del alocutario en dos poemas: "Arte poética" de Vicente Huidobro y "Fútbol" de Blanca Varela. Asimismo, se realiza una crítica de la categoría de yo poético que no permite analizar la dimensión dialógica del texto poético.

Palabras Clave: Locutor, alocutario, poesía, crítica, categoría.

https://doi.org/10.32654/CONCIENCIAEP 
Abstract

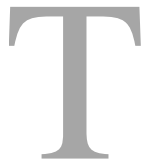

he speaker and addressee are two central figures in the poetic text. The article analyzes the role of the speaker and addressee in two poems: "Arte poética" by Vicente Huidobro and "Fútbol" by Blanca Varela. Likewise, there is a critique of the category of poetic self that does not allow us to analyze the dialogic dimension of the poetic text.

Key Words: Speaker, addressee, poetry, critic, category.

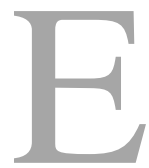

l sujeto empírico no es el que habla en un poema. Se trata de instancias distintas, pues la voz que se expresa en un texto poético es de naturaleza ficcional. Sin duda, los estudios sobre la instancia de la enunciación (Benveniste, 1970, 1997; Ducrot, 1984; Greimas y Courtés, 1990; Kerbrat-Orecchioni, 1999; Lyons, 1980) han definido a esta como el acto de producir un enunciado, el cual es concebido como la realización concreta de una frase $\mathrm{u}$ oración en un determinado momento y lugar (Ducrot y Schaeffer, 1995).

La investigación literaria sobre poesía ha utilizado de manera intuitiva e imprecisa el término "yo poético" sin tomar en cuenta que dicha categoría manifiesta poca capacidad para describir las marcas del sujeto de la enunciación en el enunciado. Además, podemos formular las siguientes preguntas: ¿a quién se dirige el yo poético? ¿Cuántos tipos de yo poético existen? ¿El yo poético está presente tanto en poemas donde se encuentra el empleo del yo gramatical como en los que se utiliza solamente la tercera persona? Estas preguntas quedan sin respuesta debido a que no hay una instancia, desde el punto de vista teórico, a la cual se dirija el yo poético. Asimismo, no existe una taxonomía rigurosa de dicha categoría de análisis. A ello hay que agregar que el concepto de yo poético manifiesta una imprecisión descriptiva, pues se emplea tanto para el análisis de poemas donde aparece la enunciación enunciada, es decir, con marcas del "yo" o del "tú", como para textos poéticos donde solamente se utiliza la tercera persona. En tal sentido, dadas las limitaciones antes enunciadas, resulta pertinente reemplazar la categoría "yo poético" por la de locutor y así plantear una pragmática del texto lírico (Fernández, 2009). Lamentablemente, en los estudios actuales, aún sigue predominando la categoría "yo poético" y ello no permite profundizar en la pragmática del texto lírico. Incluso García Bedoya (2019), quien plantea dos tipos de locutor (activo $\mathrm{y}$ pasivo) y dos clases de alocutario (figural y funcional), reemplaza el locutor activo (o en primera persona) con el término yo poético, aspecto que manifiesta una falencia desde el punto de vista teórico y repite una terminología demasiado tradicional que poco aporta al análisis minucioso de los interlocutores en un poema. 
El locutor constituye la instancia que habla en un poema. Puede ser de dos clases: el locutor personaje y el nopersonaje (Fernández, 2009). El primer tipo se observa en "Los heraldos negros" de César Vallejo, donde se afirma "Hay golpes en la vida tan fuertes... Yo no sé!" (1991, p. 61); sin embargo, hay que considerar que cuando aparece un "tú" (tácito o explícito) ya tenemos el funcionamiento de un locutor personaje porque no hay un "tú" sin un "yo" en un poema debido al carácter plenamente dialógico del lenguaje humano. El segundo tipo se revela en "El Duque" de José María Eguren (2014) donde, a lo largo del discurso poético, no hay presencia ni del "yo" ni del "tú". Ahora bien, el locutor se dirige a un alocutario (en el interior del poema). Este último puede ser representado (cuando existe un "tú") o no representado (cuando se evidencia una ausencia del mencionado "tú").

En síntesis, pueden existir tres posibilidades desde el punto de vista de los interlocutores en un texto poético. La primera es cuando hay un locutor personaje y un alocutario no representado: a esta situación se le denomina monólogo. La segunda se evidencia cuando existen un locutor personaje y un alocutario representado: dicho escenario configura un diálogo. Por último, la tercera se manifiesta en el caso de que haya un locutor no-personaje y un alocutario norepresentado: ese ámbito constituye una descripción (o reflexión) impersonal. Resulta pertinente mencionar que puede haber una locutora (por ejemplo, en un texto de Magda Portal (2010) o de Blanca Varela (2016) como "Vals del Ángelus") o una alocutaria (verbigracia, la amada en "Poema 1" de Pablo Neruda). Asimismo, se puede comprobar el funcionamiento de un locutor plural (en "La cena miserable" de César Vallejo [1991], donde se emplea el "nosotros") o un alocutario plural (en "Hombres necios" de Sor Juana Inés de la Cruz [1975], donde la locutora se dirige en segunda persona a los "Hombres necios").

\section{A) Análisis de los interlocutores y la metapoesía en “Arte poética” de Vicente Huidobro}

La crítica especializada ha subrayado el carácter pionero de Vicente Huidobro (1893-1948) en la vanguardia hispanoamericana (Costa [Ed.], 1975; Pizarro, 1994; Schopf, 2000) Un caso muy significativo es "Arte poética":

Que el verso sea como una llave Que abra mil puertas.

Una hoja cae; algo pasa volando;

Cuanto miren los ojos creado sea,

$Y$ el alma del oyente quede temblando.

Inventa mundos nuevos y cuida tu palabra;

El adjetivo, cuando no da vida, mata.

Estamos en el ciclo de los nervios.

El músculo cuelga,

Como recuerdo, en los museos;

Mas no por eso tenemos menos fuerza:

El vigor verdadero

Reside en la cabeza.

Por qué cantáis la rosa, joh Poetas!

Hacedla florecer en el poema; 
Sólo para nosotros

Viven todas las cosas bajo el Sol.

El Poeta es un pequeño Dios (Huidobro, 2012, p. 21)

El poema revela varias voces y la metapoesía. La estrofa inicial muestra la primera opción: se trata de una reflexión impersonal, pues hay un locutor nopersonaje y un alocutario no representado (no existen marcas del "yo" ni del "tú"). Sin duda, el modo subjuntivo expresa el deseo de que el verso se convierta en la apertura permanente al diálogo expresado a través de la hipérbole ("mil puertas"). A ello hay que agregar la importancia de la visión del poeta demiurgo, quien crea a partir de su percepción. No obstante, aparece el posible efecto del discurso en el receptor, pues el alma de este último recibe la potencia del enunciado pronunciado por el emisor.

En la segunda estrofa, se percibe un cambio de perspectiva, en vista de que el locutor sugiere al alocutario (un poeta, sin duda) que sea original y manifieste la conciencia crítica del poeta moderno. El uso de la forma imperativa produce una transformación de perspectiva: hay una dimensión ética de la palabra poética y, por ello, el poeta tiene la obligación de cuidarla como si fuera lo más valioso del mundo. Además, Huidobro se nutre de una concepción estética que viene del romanticismo y que subraya la imperiosa necesidad de la originalidad como principio esencial de la creación poética (López-Adorno, 1987). Posteriormente se hace referencia, de un modo más impersonal, a la importancia de evitar los ripios en un poema. A diferencia de los modernistas que se solazaban en el empleo de los adjetivos, los vanguardistas (el ultraísta Jorge Luis Borges y el creacionista Huidobro, por ejemplo) llamaron la atención sobre la necesidad de reducir el uso de los adjetivos con el fin de lograr la tan ansiada precisión en el ámbito de la elaboración formal de un texto poético (Fernández, 2005).

Después, en la tercera estrofa, predomina el locutor personaje plural (el "nosotros": "estamos" y "tenemos") que se dirige a un alocutario no representado. Esta marca de la instancia de la enunciación ("Estamos en el ciclo de los nervios", donde se manifiesta un locutor personaje plural) parece ser una velada afirmación al contexto de la primera guerra mundial, pues "Arte poética" forma parte de El espejo de agua que vio la luz en 1916 y sabemos que el sentido es una corriente continua que va de poema en poema en el interior de un determinado poemario (Bueno, 1985). En El espejo de agua se afirma en "Año nuevo": "La película mil novecientos dieciséis/ Sale de una caja.// La guerra europea.// Llueve sobre los espectadores/ Y hay un ruido de temblores" (Huidobro, 2011, p. 21). En tal sentido, "Año nuevo" ilumina el significado de "Arte poética". Cuando escribió que el vigor residía en la mente (es decir, "la cabeza"), Huidobro:

(...) no hacía más que identificarse con una tradición estética muy anterior -Leonardo: la pintura es una cosa mental一, que resurgía y se intensificaba en el arte contemporáneo. No era otra, en lo esencial, la concepción de cubismo y 
aun del futurismo. Ligado de algún modo a uno y otro, Apollinaire podía decir en uno de los poemas más célebres de Calligrammes (1918): "C'est le temps de la raison ardente" (Sucre, 2020, p. 131).

Posteriormente, en la cuarta estrofa, el locutor se dirige a un alocutario representado plural (los poetas) para sugerir a estos una determinada propuesta: el ideal no es el canto a la rosa desde una óptica meramente temática, sino la rosa como constructo formal (es decir, como figura retórica, ritmo o prosodia). Se trata del funcionamiento del campo figurativo de la metáfora (Arduini. 2000), un ámbito cognitivo que permite situar un conjunto de figuras retóricas y que implica una forma de pensar y de organizar el mundo. Luego, en la quinta estrofa, se evidencia el locutor personaje plural que orienta su palabra a un alocutario no representado. Por último, "Arte poética" concluye con una reflexión impersonal, es decir, retorna a la situación inicial desde el punto de vista de los interlocutores: la máxima final (centro de la poética creacionista) subraya el carácter demiúrgico del poeta muy distinto del dios convencional porque aquel se sustenta en el trabajo con la palabra y en una percepción no habitual del mundo.

En el poema, hay un macroacto de habla: sugerir (de ahí el uso de la forma imperativa) la necesidad imperiosa de alejarse de la mímesis clásica para crear universos ficcionales autónomos a través del empleo consciente de la racionalidad, hecho que explicita en el uso del término "cabeza" por oposición a la idea de inspiración. Además, hay la presencia de microactos de habla, por ejemplo, afirmar que es imprescindible pensar en el receptor del poema, pues se trata de enfatizar la vocación dialógica y persuasiva del discurso ("el alma del oyente quede temblando"). En otros términos, el locutor realiza actos de habla para influir en el alocutario y modificar su conducta

\section{B) Análisis de "Fútbol" de Blanca Varela}

La investigación especializada ha rastreado los antecedentes de Blanca Varela (1926-2009) en la tradición literaria peruana (Muñoz, 2007; Fernández, 2010) y en el contexto de la posguerra (Paz, 200711). Además, ha examinado los vínculos entre la pintura y su poesía (Suárez, 2003), así como ha empleado la perspectiva de género para observar cómo en la escritura de Varela hay una crítica del orden androcéntrico (Silva Santisteban, 2002).

A continuación, analizaremos el papel de los interlocutores en "Fútbol" de Varela:

\section{A Vicente y Lorenzo}

juega con la tierra como con una pelota

báilala estréllala reviéntala

\footnotetext{
${ }^{1}$ Este texto de Octavio Paz fue el prólogo a Ese puerto existe de Blanca Varela que vio la luz en 1959.
} 
no es sino eso la tierra

tú en el jardín

mi guardavalla mi espantapájaros

mi atila mi niño

la tierra entre tus pies

gira como nunca

prodigiosamente bella (Varela, 2016, p. 100)

A diferencia del poema de Huidobro, "Fútbol" revela la perspectiva del diálogo que se mantiene prácticamente a lo largo de todo el texto. Por eso, una locutora personaje (la madre) busca influir en el alocutario representado (el hijo). "Fútbol", sin duda, subvierte los roles de género impuestos tradicionalmente por el orden androcéntrico que asigna al hombre el papel de entrenador. En cambio, Varela hace que la locutora se comporte como entrenadora del equipo de fútbol, mientras que el hijo representa al futbolista que lucha en el campo de juego, metáfora de la vida. Sin embargo, el campo figurativo de la metáfora (Arduini, 2000) no termina allí. La forma de la pelota de fútbol semeja la del planeta Tierra. Por eso, la polisemia de esta última palabra supone dos posibilidades de significación: 1) la tierra asociada al mundo rural opuesta a la urbe

\section{Referencias}

Arduini, S. (2000). Prolegómenos a una teoría general de las figuras. Universidad de Murcia.

Benveniste, É. (1970). L'Appareil formel de l'énonciation. Langage, 217, 12-18. y 2) la tierra que remite al planeta Tierra. $\mathrm{Si}$ tomamos en cuenta este segundo sentido, entonces llegamos a una propuesta ecológica. La madre (la locutora) busca cambiar la actitud del hijo (el alocutario representado) en relación con el entono en el cual vive, porque estimula la capacidad creativa del niño al subrayar la necesidad de que el ser humano tenga una relación lúdica ( $\mathrm{y}$ no destructiva) con el planeta Tierra. Por ello, en la última estrofa, aparece el hijo que juega con el balón de fútbol que semeja la madre Tierra y esta se encuentra "prodigiosamente bella".

\section{Coda}

Una primera lectura de un texto de Huidobro y de otro de Varela ha permitido reconocer la importancia de estudiar los interlocutores en un poema articulados al análisis del campo figurativo de la metáfora. En el primer caso, hay una perspectiva que transita desde una reflexión impersonal a un monólogo y a un diálogo. Por el contrario, en el segundo, hay la preeminencia de un diálogo. Estos aspectos permiten comprobar la utilidad de distinguir y examinar el papel del locutor y del alocutario en un texto poético.

Benveniste, É. (1997). Problemas de lingüística general I. Siglo Veintiuno.

Bueno, Raúl (1985). Poesía hispanoamericana de vanguardia: 
procedimientos de interpretación textual. Editorial Latinoamericana.

Costa, René de (Ed.) (1975). Vicente Huidobro y el creacionismo. Editorial Taurus.

Ducrot, O. (1984). El decir y lo dicho. Hachette.

Ducrot, O. y Schaeffer, J.M (1995). Nouveau Dictionnaire encyclopédique des sciences $d u$ langage. Éditions du Seuil.

Eguren, J. M. (2014). Poesías completas. Peisa.

Fernández Cozman, C. (2005). La soledad de la página en blanco. Ensayos sobre lírica peruana contemporánea. Fondo Editorial de la Facultad de Letras y Ciencias Humanas de la Universidad Nacional Mayor de San Marcos.

Fernández Cozman, C. ([2001] 2009). Rodolfo Hinostroza y la poesía de los años sesenta. 2da. edición ampliada y corregida. Universidad de Ciencias y Humanidades.

Fernández Cozman, C. (2010). Casa, cuerpo. La poesía de Blanca Varela frente al espejo. Universidad San Ignacio de Loyola.

García-Bedoya M. C. (2019). Hermenéutica literaria. Una introducción al análisis de textos narrativos $y$ poéticos. Facultad de Letras y Ciencias Humanas de la Universidad Nacional Mayor de San Marcos y Cátedra Vallejo.
Greimas, J. A. y Courtés, J. (1990). Semiótica. Diccionario razonado de la teoría del lenguaje. [Traducción de Enrique Ballón Aguirre y Hermis Campodónico Carrión]. Gredos.

Huidobro, V. (2011). El espejo de agua y Ecuatorial. Pequeño Dios Editores.

Huidobro, V. (2012). Poesía y creación. Selección y prólogo de Gabriele Morelli. Fundación Banco Santander.

Kerbrat-Orecchioni, $\quad$ C. (1999). L'Énonciation. De la subjectivité dans le langage. Armand Colin.

López-Adorno, P. (1987). Lectura ideológica-estética de Altazor. Revista de crítica literaria latinoamericana, 13 (25), 51-80.

Lyons, J. (1980). Semántica. Barcelona: Teide.

Muñoz Carrasco, O. (2007). Sigiloso desvelo. La poesía de Blanca Varela. Pontificia Universidad Católica del Perú.

Paz, O. (2007). Destiempos de Blanca Varela. En Dreyfus, M y Silva Santisteban, R. (Ed.). Nadie sabe mis cosas. Reflexiones en torno a la poesía de Blanca Varela (pp. 2933). Fondo Editorial del Congreso de la República.

Pizarro, A. (1994). Sobre Huidobro y las vanguardias. Editorial de la Universidad de Santiago.

Portal, M. (2010). Obra poética completa. Edición, prólogo, notas y cronología 
de Daniel R. Reedy. Fondo de Cultura Económica del Perú.

Schopf, F. (2000). Del vanguardismo a la antipoesía. Ensayos sobre la poesía en Chile. Lom.

Silva Santisteban, R. (2002). Ejercicios materiales: aprender la inmortalidad. Ajos y zafiros, 3-4, 2743.

Sor Juana Inés de la Cruz. (1975). Antología poética. Atlántida.

Suárez, M. (2003). Espacio pictórico y espacio poético en la obra de Blanca Varela. Editorial Verbum.
Sucre, G. (2020). La Máscara, La Transparencia. Fondo de Cultura Económica.

https://es.scribd.com/doc/279596 429/Sucre-Guillermo-La-MascaraLa-Transparencia.

Varela, B. (2016). Poesía reunida 19492000. Casa de Cuervos y Sur, librería anticuaria.

Vallejo, C. (1991). Obra poética. Edición crítica, prólogo, bibliografía e índices de Ricardo González Vigil. Banco de Crédito del Perú. (Obras completas, t. 